\title{
The united airways concept: from bench to bedside
}

\author{
G.J. Braunstahl
}

Monaldi Arch Chest Dis 2007; 67: 2, 95-101.

Department of Pulmonary Medicine, St. Franciscus Gasthuis, Rotterdam, The Netherlands.

Correspondence: G.J. Braunstahl M.D., Ph.D., Department of Pulmonary Medicine, St. Franciscus Gasthuis, Kleiweg 500, 3045 PM Rotterdam, the Netherlands; e-mail: g.braunstahl@sfg.nl

\section{Introduction}

Allergic rhinitis and asthma frequently occur together. Almost $40 \%$ of the allergic rhinitis patients have lower airways involvement, whereas more than $80 \%$ of allergic asthma patients have concomitant rhinitis symptoms. The latter becomes close to $95 \%$ when a careful nasal history is taken and physical examination is performed [1].

For many years allergic asthma has been characterised by a history of episodes of cough, dyspnea, shortness of breath, chest tightness and wheezing, combined with variable bronchoconstriction and/or bronchial hyperresponsiveness (BHR). To date, mucosal inflammation is also considered an important hallmark of asthma [2]. Allergic rhinitis is primarily based on a typical history of sneezing, rhinorrhoea, eye symptoms and nasal obstruction. As with allergic asthma, the atopic status needs to be confirmed [3]. The distinction between allergic asthma and rhinitis is sometimes difficult to make since symptom perception is widely variable; lung function can be normal in mild asthmatics and, although BHR is a constant feature of asthma, it is also frequently present in allergic rhinitis [4]. This review provides an overview of recent epidemiological and immunopathological evidence concerning the link between upper and lower airways in allergic disease and its therapeutic implications.

\section{The nose as protector of the airways}

The nose and lungs are anatomically and physiologically closely related organs. Nevertheless, differences in anatomy and function between the nose and lungs have led to the division of the respiratory tract into upper and lower airways. The upper airways, from the nostrils to the vocal cords, have been the domain of the E.N.T. surgeon for many years, while the airways underneath the vocal cords - comprising the tracheo-bronchial tree, the respiratory bronchioles, alveolar ducts and alveolar sacs - have been the work area of the pulmonologist. This arbitrary division contributes to the fact that asthma and allergic rhinitis are still considered as two separate entities and are treated accordingly.

It is no coincidence that the nose is located at the beginning of the respiratory tract. The nose plays an important role in air-conditioning and host defense. While breathing through the nose, the inhaled air is heated and humidified due to close contact with the vascular network in the nasal mucosa. Moreover, the nose has an impressive filter capacity: inhaled particles, $10 \mu \mathrm{m}$ and larger, get trapped in the nose and will be transported with the mucus to the oropharynx [5]. Micro-organisms and allergens in sensitised people can activate resident inflammatory cells leading to a localised immune response. The initial response is characterized by mast cell degranulation and Tcell activation. These two cells release adhesion molecules, cytokines, chemokines and vasoactive products. This results in the recruitment of leukocytes, such as neutrophils, basophils and eosinophils, from the circulation to the exposed area. Therefore, the nose is the first line of defense in protecting the lower airways from potentially harmful agents [6]. In allergic rhinitis, the nasal function is often impaired which can affect the lower airways as well.

\section{The association between allergic rhinitis and asthma}

Allergic rhinitis and asthma frequently occur together and are both manifestations of the $\operatorname{IgE}$ mediated atopic syndrome. The prevalence of allergic rhinitis and asthma varies all over the world and is associated with a "westernised" lifestyle [7]. In Western-Europe $10-15 \%$ of the general population have asthma symptoms, while around $20 \%$ of the people suffer from allergic rhinitis (figure 1). Allergic rhinitis patients have an increased risk of 


\section{Prevalence asthma and rhinitis}

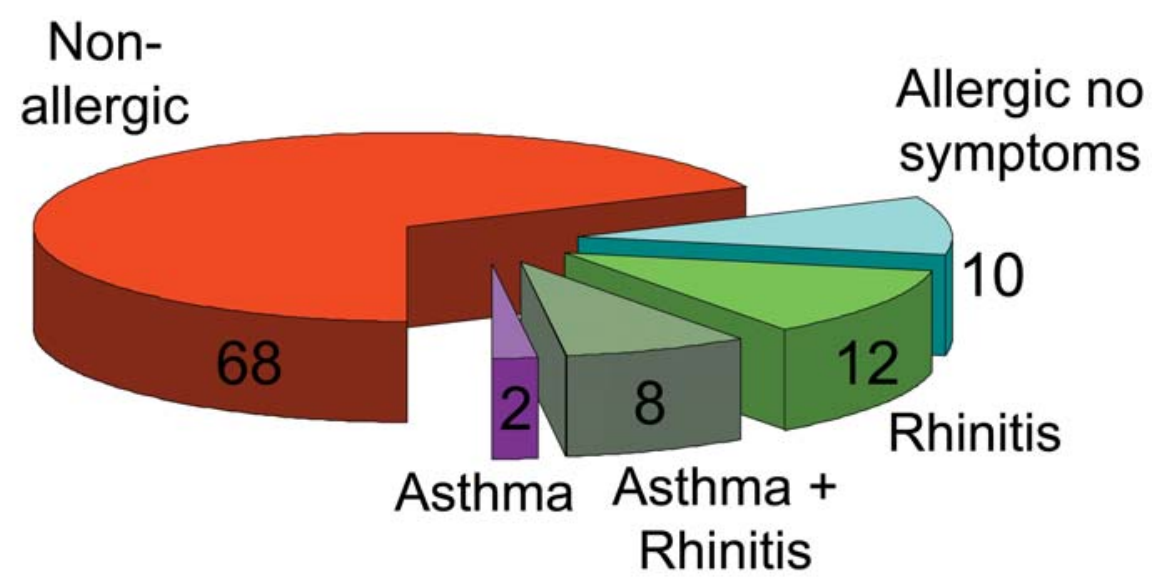

Fig. 1. - Prevalence of asthma and rhinitis.

developing asthma, especially when BHR is present [8]. In the majority of the allergic rhinitis patients, the rhinitis symptoms start before the onset of asthma [9]. Between 80-95 \% of all asthmatic patients have rhinitis [10]. The epidemiological data is the foundation on which the united airways concept is build.

The immuno-pathological aspects of allergic rhinitis and asthma have been extensively studied in the past decade. Allergic asthma and allergic rhinitis are characterised by a similar inflammatory process in which mast cells and eosinophils appear to be the major effector cells $[10,11]$. The migration of eosinophils from the blood into the tissue is dependent on the expression of cytokines and adhesion molecules (figure 2). Eosinophilia in bronchial mucosa is regarded as one of the hallmarks of allergic asthma [2]. However, signs of lower airway inflammation have also been found in allergic rhinitis patients without asthma, in terms of an increase in interleukin (IL)-5 and eosinophil numbers $[12,13]$. In asthmatic patients without rhinitis, on the other hand, increased numbers of eosinophils were present in nasal mucosa [14]. The number of nasal eosinophils is positively correlated with the degree of BHR [15]. In conclusion, allergic rhinitis and asthma often co-exist and they share immunopathological features indicating a common etiology.

\section{Risk factors involved in the development of allergic airways disease}

Allergic rhinitis and asthma are multifactorial disorders. A positive family history of atopic diseases is considered as an important risk factor for the development of allergic rhinitis and asthma
[16]. Genetic studies have demonstrated the involvement of genes coding for IgE and BHR [17]. Despite the fact that $30 \%$ of the population has a atopic constitution, only two-third develops clinical symptoms. Therefore, environmental influences seem to be needed for the final expression of allergic disease as well. Exposure to allergens, viral respiratory tract infections, cigarette smoke and other irritants are also important risk factors involved in the development of allergic airways disease [18]. However, reduction of allergen exposure in childhood offers some, but certainly not total protection against the development of respiratory symptoms later on in life [19]. Moreover, several studies have shown that exposure to endotoxins early in life may prevent against allergic rhinitis and asthma [20]. Therefore, genetic predisposition and environmental factors are both involved in the development of allergic airways disease.

\section{The mechanisms of nasobronchial interaction}

Allergen provocation studies in animals and human have provided a useful model to better understand the crosslink between nose and lungs. Nasal provocation in allergic rhinitis subjects induced bronchial inflammation characterised by increased endothelial expression of adhesion molecules, such as VCAM and E-selectin, as well as an influx of eosinophils [13]. Vice versa, segmental bronchial provocation in the same subset of allergic patients showed similar results in nasal mucosa $[21,22]$. The inflammatory changes were accompanied by airway symptoms and decreased airway patency.

Although several mechanisms of nasobronchial interaction have been proposed in the 


\section{Airway inflammation}

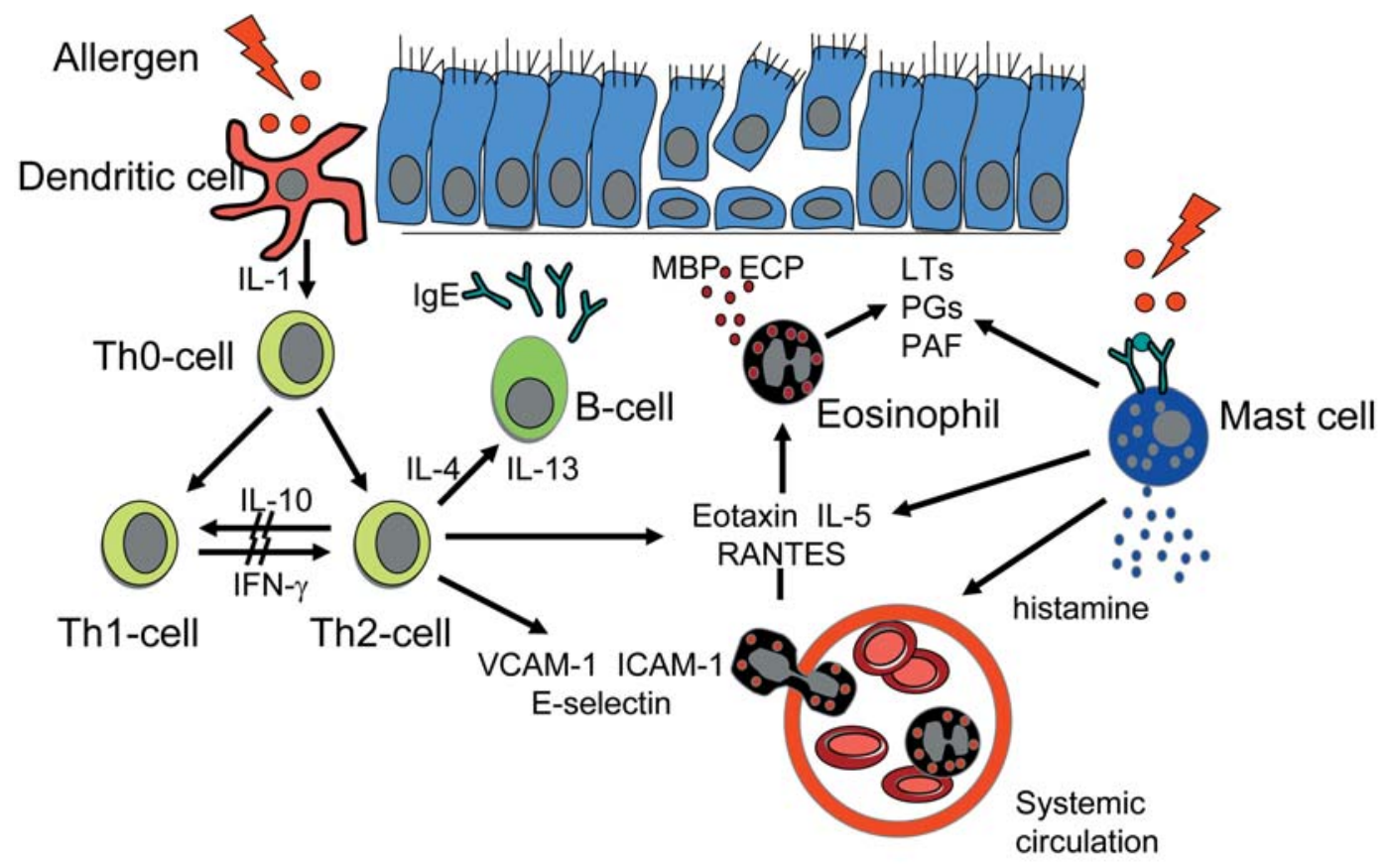

Fig. 2. - Mechanisms of migration of eosinophils from the blood into the tissue.

past (altered breathing pattern, nasobronchial reflex and aspiration of nasal contents), to date most evidence points towards a systemic pathway.

\section{Altered breathing pattern}

As stated earlier, the main functions of the nose are to filter, warm up and humidify inhaled air. In allergic rhinitis these functions are impaired which has consequences for the lower airways as well. The breathing of cold air through the mouth leads to a decrease in $\mathrm{FEV}_{1}$ in asthmatic patients, while nasal breathing prevents this [23]. Moreover, there is a clear association between the severity of allergic rhinitis symptoms and the development of asthma [9]. Also, other nasal obstructive disorders, such as nasal polyposis and chronic sinusitis, influence the course of asthma in a negative way. Functional endoscopic sinus surgery leading to restored nasal airway patency improves asthma symptoms [24].

\section{Nasobronchial reflex}

A neural pathway between nose and lungs is another possibility for nasobronchial interaction. This fast-acting mechanism has been mentioned as an initiator of bronchospasm after nasal cold air exposure [25]. The mechanical and chemical stimulation of nasal, laryngeal and tracheal receptors may cause sneezing, cough or bronchospasm protecting the lower airways from potential harmful agents. However, other studies demonstrate that this bronchoconstrictive effect only takes place after oral inhalation and not after nasal inhalation [23]. In addition, nasal provocation with methacholine and allergen resulted in increased airway resistance and bronchial hyperresponsiveness after several hours, however no direct bronchial response was noted [26, 27]. Although neural reflex mechanisms may be present after cold air inhalation, there is no evidence to show that they play a role after allergen exposure.

\section{Aspiration}

Several studies have demonstrated a clear relationship between post nasal drip and cough. However, there is no evidence of aspiration of nasal secretions or any direct contact with the bronchial mucosa. After instillation of radio-active labeled allergen in the sinuses of allergic rhinitis, patients increased uptake was seen in the gastro-intestinal tract, but not in the lower airways. It is probable that the triggering of the pharyngeal-laryngeal receptors is responsible for coughing in the context of post nasal drip. Aspiration may play a role in patients with decreased level of consciousness and nonfunctioning cough reflex. However, the role of aspiration in the development of asthma is doubtful.

\section{Systemic inflammation}

Several studies in animals and patients with allergic rhinitis, asthma and other atopic diseases consequently show an increase of inflammatory 
cells and mediators in the circulation after allergen exposure. Absorption of inflammatory products of mast cells and T-lymphocytes in the systemic circulation leads to the release of eosinophils and their precursors (CD34+) from the bone marrow into the circulation. This systemic allergic response results in an increased expression of adhesion molecules followed by an influx of eosinophils and basophils from the blood into the airway mucosa. More severe nasal inflammation is associated with increased bronchial hyperresponsiveness in patients with allergic rhinitis and asthma.

In conclusion, local allergen challenge in nose or lungs is not limited to the place of the initial allergen exposure, but it extends to the systemic circulation and the entire airway (figure 3 ). This has a profound impact on daily clinics. It stresses the importance of a diagnostic strategy involving both ends of the respiratory tract. The systemic link between allergic rhinitis and asthma provides a rationale for a systemic approach targeting the underlying allergic disorder.

\section{Therapeutic implications}

The "Global Initiative for Asthma" (GINA) guidelines advise a stepwise approach of asthma dependent on severity in which the standard therapy comprises inhaled $\beta 2$-agonists and corticosteroids [2]. Leukotriene receptor antagonists (LTRA), cromoglycates or theophyllines can be added later (step 3) when no asthma control can be achieved with standard therapy. The recommenda- tions of the guidelines, however, do not take into account the systemic aspects of asthma. In 2001 the ARIA document (Allergic Rhinitis and its Impact on Asthma) was published, in which the systemic character of asthma was emphasised [3]. This guideline has formed an important addition to the GINA guidelines (figure 4).

Medical treatment of allergic rhinitis in patients with concurrent asthma reduces the risk of asthma-related events [28]. In a recent case-control study based on health insurance claims, Corren et al found a significant reduction in hospital admissions or emergency room visits in asthma patients treated with nasal corticosteroids and/or second generation antihistamines [29]. Insight into the risk factors responsible for allergic airways disease and the interaction between the involved organs results in a better therapeutic approach of the global airway allergy syndrome.

\section{Allergen avoidance}

Various guidelines recommend allergen avoidance as a useful intervention in allergic rhinitis and asthma [3]. Most of the evidence, however, is based on expert opinion. Although it is a well known fact that house dust mite (HDM) sensitised patients improve in a high-altitude, allergen free environment, reduction in allergen load is often not effective. Decreased exposure to indoor allergens during infancy offers limited protection against the development of respiratory symptoms in a high-risk population [19]. Impermeable mattress covers significantly decrease HDM load in

\section{Concept allergic airways disease}

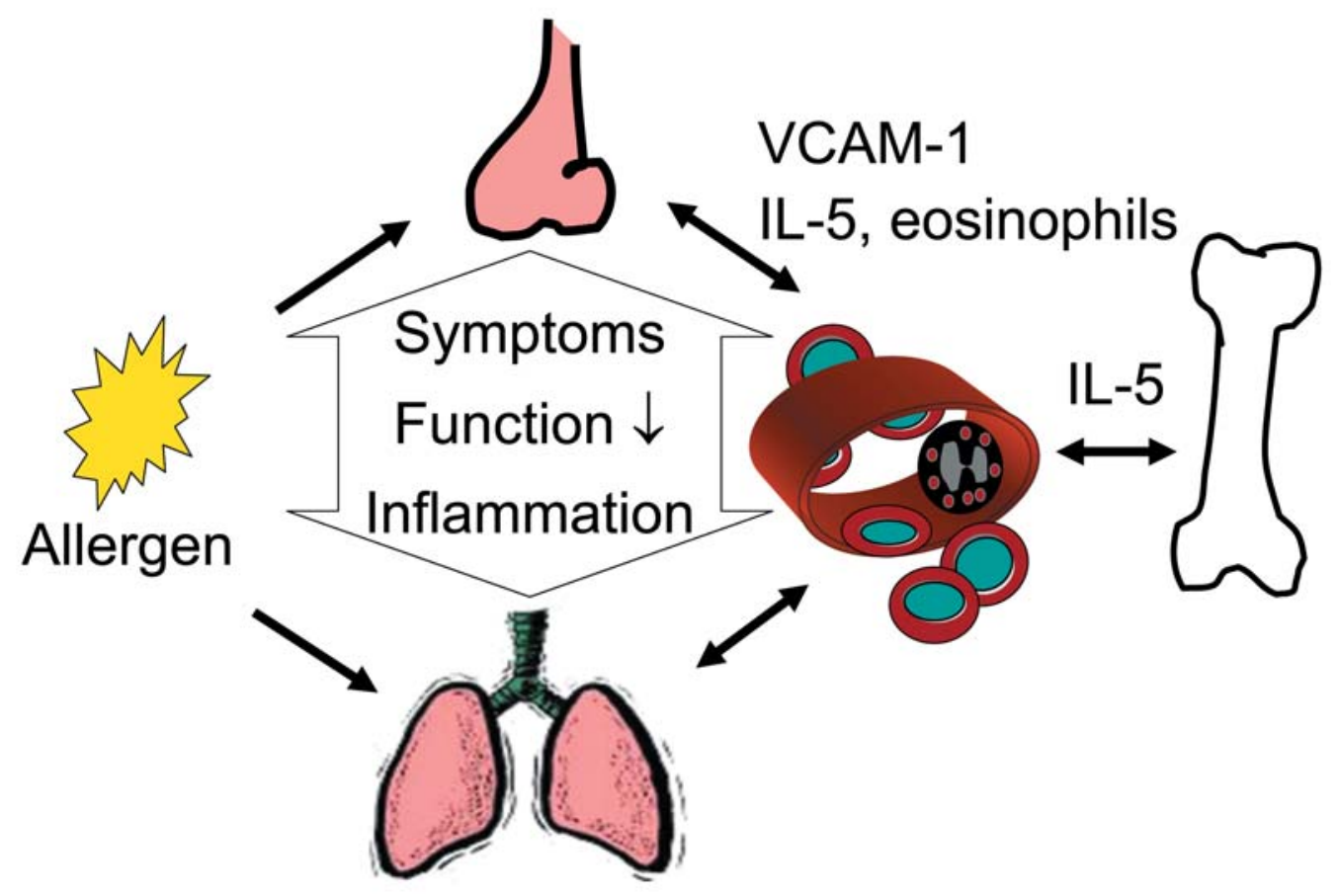

Fig. 3. - Current concept of allergic airways disease.

(Modified from Current Opinion in Pulmonary Medicine 2003; 9: 46-51). 


\section{Current therapy}

\begin{tabular}{|c|c|c|}
\hline & ASTHMA & RHINITIS \\
\hline Beta $_{2}$ agonists & + & $\cdot$ \\
\hline Alpha agonists & - & + \\
\hline Antihistamins & \pm & + \\
\hline LTRA's & + & + \\
\hline Nasal corticosteroids & \pm & + \\
\hline Inhaled corticosteroids & + & \pm \\
\hline Theophylline & + & - \\
\hline Anti-lgE & + & + \\
\hline Immunotherapy & \multicolumn{2}{|c|}{ selected patients } \\
\hline $\begin{array}{l}+=\text { positive effect } \\
==\text { no effect } \\
\pm=\text { possible effect }\end{array}$ & \multicolumn{2}{|c|}{ Bousquet (ARIA), J Allergy Clin Immunol 2001} \\
\hline
\end{tabular}

Fig. 4. - Therapeutic options for asthma rhinitis.

allergic rhinitis patients [30] and asthmatics [31], however, the intervention has no effect on clinical parameters, such as symptoms and lung function. An approach combining several measures (smooth surface, air filters and bed covers) may be more successful, but needs further study.

\section{Topical treatment}

Systemic administration of $\beta 2$-agonists, theophylline and corticosteroids has been available for more than 50 years, but is now largely restricted to a clinical setting. The development of inhalation therapy with $\beta 2$-agonists, anticholinergics and cromoglycate combined a fast local effect with less toxicity. Inhalation corticosteroids have been the cornerstone of asthma treatment for over 25 years [32]. Since their introduction both mortality and the number of hospital admissions due to asthma have dramatically decreased. Inhalation steroids guarantee good local control of airway inflammation, however the effect on the systemic aspects of allergic inflammation is minimal.

Nasal corticosteroids have been previously demonstrated to improve asthma symptoms and stabilize BHR in allergic rhinitis patients with seasonal asthma [33, 34]. Moreover, nasal therapy with beclomethasone was as effective as inhaled beclomethasone in alleviating bronchial symptoms and improving lung function [35]. However, these studies were performed with beclomethasone nasal spray, which is known to have some uptake into the systemic circulation. Systemic bioavailability of the medication may have caused the effect on the lower airways.

Fluticasone propionate (FP), a corticosteroid with virtually no systemic bioavailability after nasal application, had clinical effects on the lower airways of asthmatics with co-existing allergic rhinitis after inhalation, but not after nasal administration alone [36]. Combination treatment with nasal and inhaled FP resulted in the greatest reduction of sputum eosinophils. Also, in another large study concerning patients with persistent asthma and seasonal allergic rhinitis no additional effect on lung function parameters and asthma symptoms was detected when nasal FP was added to inhaled FP [37]. However, these two trials were limited by a short follow-up time of only four weeks. In the recent study by Stelmach et al., the beneficial bronchial effect of nasal steroids started after 4 weeks [35]. Although nasal corticosteroids are very useful for the local treatment of allergic rhinitis, the direct measurable effect on the lower airways seems to be of minor clinical significance. Nevertheless, nasal corticosteroids may play a role in asthma by preventing asthma exacerbations in patients with asthma and co-existing allergic rhinitis [28, 29].

\section{Systemic treatment}

The high prevalence of allergic rhinitis among asthmatic patients and the presence of proinflammatory mediators in the systemic circulation are important arguments in favour of a systemic treatment. Systemic therapy with $\beta$-agonists, theophylline and corticosteroids has been used in the past to effectively treat asthma and rhinitis, but their use is limited by side effects.

Mucosal inflammation in asthma and allergic rhinitis is characterised by an increase in cysteinyl leukotriens (CysLT's). CysLT's are produced by inflammatory cells, such as mast cells, eosinophils, basophils and macrophages. CysLT's exert several effects on the respiratory system, such as airway oedema, mucus secretion, eosinophilia and bronchus constriction. Leukotriene receptor antagonists (LTRA's) have proven to be effective in both asthma [38] and rhinitis [39]. However, LTRA's are less effective than antihistamines and nasal steroids [37, 40]. LTRA's have an anti-inflammatory effect, which is additional to the effect of nasal and inhaled corticosteroids and explains the steroid-sparing properties of the drug [41].

Antihistamines are the medication of choice in the treatment of intermittent allergic rhinitis [3]. In the bronchi antihistamines bind to H1-receptors on smooth muscle cells. Although histamine release plays a role in the pathology of both asthma and rhinitis, antihistamines are not frequently used in the treatment of asthma. Nevertheless second generation antihistamines have proved to be more effective than placebo [42] and as effective as montelukast [43] in reducing asthma symptoms and improving lung function in patients with seasonal allergic rhinitis and asthma.

Specific immunotherapy (SIT) may prevent the natural progression of allergic rhinitis to bronchial asthma. This is particularly the case with patients who are allergic to grass pollen, SIT is extremely effective with a response rate of $80-90 \%$ [44]. The results of SIT in patients with house dust mite allergy are less spectacular [45]. A three year 
course of SIT in children [46] and adults [47] with seasonal allergic rhinitis significantly reduced the risk of developing asthma. Sublingual immunotherapy (SLIT) has a safer profile than SIT and is known to be effective in allergic rhinitis. Whether SLIT also has a beneficial effect on asthma is not well established, although new data seems promising. In a recent study, SLIT also reduced lower airway symptoms, $\mathrm{FEV}_{1}$ and bronchodilator use in adult patients with rhinitis and asthma, who were monosensitized to birch [48]. In a comparative study between nasal steroids (NS) and short preseason SIT in patients with allergic rhinitis and asthma, NS appeared to be more effective in local disease control than SIT. SIT, however, was able to have a positive influence on systemic and bronchial parameters in these patients, while NS had no apparent effect on the lower airways [49].

Anti-IgE antibodies are promising tools in asthma and rhinitis therapy as it targets one of the main initiators of the inflammatory cascade in allergic airway disease. Apart from SIT it is the only therapy that has immunomodulating effects. Omalizumab, a humanized monoclonal anti-IgE antibody, has been shown to be useful in asthma, since it reduced symptoms, asthma exacerbations and the need for steroids [50]. Treatment with omalizumab resulted in a significant decrease of eosinophils in the induced sputum of patients with mild persistent asthma [51]. So far, there have been no studies comparing the efficacy of omalizumab and ICS. Although omalizumab reduced nasal allergic inflammation and nasal symptom scores, its benefit in allergic rhinitis - particularly as a steroid-sparing agent - has yet to be determined.

\section{Conclusion}

Despite the many similarities between allergic rhinitis and asthma with regard to immunopathology, interaction processes and treatment options, a combined diagnostic and therapeutic approach of both upper and lower airways is still not widely implemented. This insight requires a close collaboration between medical specialties involved in treating allergic airway disease. The high prevalence of allergic rhinitis among asthma patients and the presence of inflammatory cells and mediators in the systemic circulation of atopic individuals, stresses the importance of a more systemic approach. Since single nasal treatment has shown to be insufficient in controlling asthma, other treatment options, such as LTRA's, H1-antihistamines, immunotherapy and Anti-IgE, need to be considered in the treatment of allergic rhinitis and asthma.

\section{References}

1. Linneberg A, Henrik Nielsen N, Frolund L, Madsen F, Dirksen A, Jorgensen T. The link between allergic rhinitis and allergic asthma: a prospective populationbased study. The Copenhagen Allergy Study. Allergy 2002; 57: 1048-52.
2. Global strategy for asthma management and prevention: NHLBI/WHO Workshop Report, 2002.

3. Bousquet J, Van Cauwenberge P, Khaltaev N. Allergic rhinitis and its impact on asthma. J Allergy Clin Immunol 2001; 108: S147-334.

4. Stevens WJ, Vermeire PA, van Schil LA. Bronchial hyperreactivity in rhinitis. Eur J Respir Dis Suppl 1983; 128: $72-80$

5. Watelet JB, Van Cauwenberge P. Applied anatomy and physiology of the nose and paranasal sinuses. Allergy 1999; 54: 14-25.

6. Lipworth BJ, White PS. Allergic inflammation in the unified airway: start with the nose. Thorax 2000; 55: 878-81.

7. Worldwide variation in prevalence of symptoms of asthma, allergic rhinoconjunctivitis, and atopic eczema: ISAAC. The International Study of Asthma and Allergies in Childhood (ISAAC) Steering Committee. Lancet 1998; 351: 1225-32.

8. Braman SS, Barrows AA, DeCotiis BA, Settipane GA, Corrao WM. Airway hyperresponsiveness in allergic rhinitis. A risk factor for asthma. Chest 1987; 91: 671-4.

9. Leynaert B, Neukirch C, Kony S, et al. Association between asthma and rhinitis according to atopic sensitization in a population-based study. J Allergy Clin Immunol 2004; 113: 86-93.

10. Busse WW, Calhoun WF, Sedgwick JD. Mechanism of airway inflammation in asthma. Am Rev Respir Dis 1993; 147: S20-4.

11. Bousquet J, Vignola AM, Campbell AM, Michel FB. Pathophysiology of allergic rhinitis. Int Arch Allergy Immunol 1996; 110: 207-18.

12. Beeh KM, Beier J, Kornmann O, Meier C, Taeumer T, Buhl R. A single nasal allergen challenge increases induced sputum inflammatory markers in non-asthmatic subjects with seasonal allergic rhinitis: correlation with plasma interleukin-5. Clin Exp Allergy 2003; 33: 475-82.

13. Braunstahl GJ, Overbeek SE, Kleinjan A, Prins JB, Hoogsteden HC, Fokkens WJ. Nasal allergen provocation induces adhesion molecule expression and tissue eosinophilia in upper and lower airways. J Allergy Clin Immunol 2001; 107: 469-76.

14. Gaga $\mathrm{M}$, Lambrou $\mathrm{P}$, Papageorgiou $\mathrm{N}$, et al. Eosinophils are a feature of upper and lower airway pathology in non-atopic asthma, irrespective of the presence of rhinitis. Clin Exp Allergy 2000; 30: 663-9.

15. Ciprandi G, Vizzaccaro A, Cirillo I, Tosca M, Massolo A, Passalacqua G. Nasal eosinophils display the best correlation with symptoms, pulmonary function and inflammation in allergic rhinitis. Int Arch Allergy Immunol 2005; 136: 266-72. Epub 2005 Feb 17.

16. Aberg N. Familial occurrence of atopic disease: genetic versus environmental factors. Clin Exp Allergy 1993; 23: 829-34.

17. Barnes KC. Evidence for common genetic elements in allergic disease. J Allergy Clin Immunol 2000; 106: S192-200.

18. Leynaert B, Neukirch F, Demoly P, Bousquet J. Epidemiologic evidence for asthma and rhinitis comorbidity. J Allergy Clin Immunol 2000; 106: S201-5.

19. Custovic A, Simpson BM, Simpson A, Kissen P, Woodcock A. Effect of environmental manipulation in pregnancy and early life on respiratory symptoms and atopy during first year of life: a randomised trial. Lancet 2001; 358: 188-93.

20. Leynaert B, Neukirch C, Jarvis D, Chinn S, Burney P, Neukirch F. Does living on a farm during childhood protect against asthma, allergic rhinitis, and atopy in adulthood? Am J Respir Crit Care Med 2001; 164: 1829-34.

21. Braunstahl GJ, Kleinjan A, Overbeek SE, Prins JB, Hoogsteden HC, Fokkens WJ. Segmental bronchial 
provocation induces nasal inflammation in allergic rhinitis patients. Am J Respir Crit Care Med 2000; 161: 2051-7.

22. Braunstahl GJ, Overbeek SE, Fokkens WJ, et al. Segmental bronchoprovocation in allergic rhinitis patients affects mast cell and basophil numbers in nasal and bronchial mucosa. Am J Respir Crit Care Med 2001; 164: 858-65.

23. McLane ML, Nelson JA, Lenner KA, et al. Integrated response of the upper and lower respiratory tract of asthmatic subjects to frigid air. J Appl Physiol 2000; 88: 1043-50.

24. Dunlop G, Scadding GK, Lund VJ. The effect of endoscopic sinus surgery on asthma: management of patients with chronic rhinosinusitis, nasal polyposis, and asthma. Am J Rhinol 1999; 13: 261-5.

25. Fontanari P, Burnet H, Zattara-Hartmann MC, Jammes $Y$. Changes in airway resistance induced by nasal inhalation of cold dry, dry, or moist air in normal individuals. J Appl Physiol 1996; 81: 1739-43.

26. Littell NT, Carlisle CC, Millman RP, Braman SS. Changes in airway resistance following nasal provocation. Am Rev Respir Dis 1990; 141: 580-3.

27. Corren J, Adinoff AD, Irvin CG. Changes in bronchial responsiveness following nasal provocation with allergen. J Allergy Clin Immunol 1992; 89: 611-8.

28. Crystal-Peters J, Neslusan C, Crown WH, Torres A. Treating allergic rhinitis in patients with comorbid asthma: the risk of asthma-related hospitalizations and emergency department visits. J Allergy Clin Immunol 2002; 109: 57-62.

29. Corren J, Manning BE, Thompson SF, Hennessy S, Strom BL. Rhinitis therapy and the prevention of hospital care for asthma: a case-control study. J Allergy Clin Immunol 2004; 113: 415-9.

30. Terreehorst I, Hak E, Oosting AJ, et al. Evaluation of impermeable covers for bedding in patients with allergic rhinitis. N Engl J Med 2003; 349: 237-46.

31. Woodcock A, Forster L, Matthews E, et al. Control of exposure to mite allergen and allergen-impermeable bed covers for adults with asthma. N Engl J Med 2003; 349: 225-36.

32. Barnes PJ. Drugs for asthma. Br J Pharmacol 2006; 147: S297-303.

33. Welsh PW, Stricker WE, Chu CP, et al. Efficacy of beclomethasone nasal solution, flunisolide, and cromolyn in relieving symptoms of ragweed allergy. Mayo Clin Proc 1987; 62: 125-34.

34. Corren J, Adinoff AD, Buchmeier AD, Irvin CG. Nasal beclomethasone prevents the seasonal increase in bronchial responsiveness in patients with allergic rhinitis and asthma. J Allergy Clin Immunol 1992; 90: 250-6.

35. Stelmach R, Nunes MdPT, Ribeiro M, Cukier A. Effect of treating allergic rhinitis with corticosteroids in patients with mild-to-moderate persistent asthma. Chest 2005; 128: 3140-3147.

36. Dahl R, Nielsen LP, Kips J, et al. Intranasal and inhaled fluticasone propionate for pollen-induced rhinitis and asthma. Allergy 2005; 60: 875-81.

37. Nathan RA, Yancey SW, Waitkus-Edwards K, et al. Fluticasone propionate nasal spray is superior to Mon- telukast for allergic rhinitis while neither affects overall asthma control. Chest 2005; 128: 1910-1920.

38. Busse W, Kraft M. Cysteinyl leukotrienes in allergic inflammation: strategic target for therapy. Chest 2005; 127: $1312-26$

39. Borish L. The role of leukotrienes in upper and lower airway inflammation and the implications for treatment. Ann Allergy Asthma Immunol 2002; 88: 16-22.

40. Pullerits T, Praks L, Skoogh BE, Ani R, Lotvall J. Randomized placebo-controlled study comparing a leukotriene receptor antagonist and a nasal glucocorticoid in seasonal allergic rhinitis. Am J Respir Crit Care Med 1999; 159: 1814-8.

41. Price DB, Hernandez D, Magyar P, et al. Randomised controlled trial of montelukast plus inhaled budesonide versus double dose inhaled budesonide in adult patients with asthma. Thorax 2003; 58: 211-6.

42. Reinartz SM, Overbeek SE, Kleinjan A, et al. Desloratadine reduces systemic allergic inflammation following nasal provocation in allergic rhinitis and asthma patients. Allergy 2005; 60: 1301-7.

43. Baena-Cagnani CE, Berger WE, DuBuske LM, et al. Comparative effects of desloratadine versus montelukast on asthma symptoms and use of beta 2-agonists in patients with seasonal allergic rhinitis and asthma. Int Arch Allergy Immunol 2003; 130: 307-13.

44. Abramson MJ, Puy RM, Weiner JM. Is allergen immunotherapy effective in asthma? A meta-analysis of randomized controlled trials. Am J Respir Crit Care Med 1995; 151: 969-74.

45. Gruber W, Eber E, Mileder P, Modl M, Weinhandl E, Zach MS. Effect of specific immunotherapy with house dust mite extract on the bronchial responsiveness of paediatric asthma patients. Clin Exp Allergy 1999; 29: 176-81.

46. Moller C, Dreborg S, Ferdousi HA, et al. Pollen immunotherapy reduces the development of asthma in children with seasonal rhinoconjunctivitis (the PATstudy). J Allergy Clin Immunol 2002; 109: 251-6.

47. Polosa R, Li Gotti F, Mangano G, et al. Effect of immunotherapy on asthma progression, BHR and sputum eosinophils in allergic rhinitis. Allergy 2004; 59: 1224-8.

48. Marogna M, Spadolini I, Massolo A, Canonica GW, Passalacqua G. Clinical, functional, and immunologic effects of sublingual immunotherapy in birch pollinosis: a 3-year randomized controlled study. J Allergy Clin Immunol 2005; 115: 1184-8.

49. Rak S, Heinrich C, Jacobsen L, Scheynius A, Venge P. A double-blinded, comparative study of the effects of short preseason specific immunotherapy and topical steroids in patients with allergic rhinoconjunctivitis and asthma. J Allergy Clin Immunol 2001; 108: 921-8.

50. Holgate ST, Djukanovic R, Casale T, Bousquet J. Anti-immunoglobulin E treatment with omalizumab in allergic diseases: an update on anti-inflammatory activity and clinical efficacy. Clin Exp Allergy 2005; 35: 408-16.

51. Djukanovic R, Wilson SJ, Kraft M, et al. Effects of treatment with anti-immunoglobulin E antibody omalizumab on airway inflammation in allergic asthma. Am J Respir Crit Care Med 2004; 170: 583-93. 